\title{
Complexity in manufacturing systems and its measures: a literature review
}

\section{Bugra Alkan*, Daniel A. Vera, Mussawar Ahmad, Bilal Ahmad and Robert Harrison}

\author{
Automation Systems Group, \\ WMG, \\ University of Warwick, \\ CV4 7AL, Coventry, West Midlands, UK \\ Email: B.Alkan@warwick.ac.uk \\ Email: D.A.Vera@warwick.ac.uk \\ Email: mussawar.ahmad@warwick.ac.uk \\ Email: B.Ahmad@warwick.ac.uk \\ Email: Robert.Harrison@warwick.ac.uk \\ ${ }^{*}$ Corresponding author
}

\begin{abstract}
Complexity in manufacturing systems still remains a challenge and leads to operational issues and increased production cost. In this paper, drivers of complexity and typical symptoms of complex manufacturing systems are identified. A comprehensive review of studies published within the last two decades to assess manufacturing system complexity are presented. The key contributions of this review are: 1) a classification of complexity assessment methods based on perceived complexity symptoms; 2 ) a comprehensive review of assessment methods with cross-evaluation to identify appropriate use based on available data; 3 ) recommendations for the wider academic and industrial community, based on research trends identified in the literature, as to how complexity assessment should be addressed in the future. It is concluded that the assessment of complexity is necessary so that it can be controlled effectively, however the industry suffers from a lack of practical tools to support in this endeavour.
\end{abstract}

[Received 23 December 2016; Revised 18 August, 14 October 2017; Accepted 22 October, 2017]

Keywords: complexity; manufacturing systems; complexity metrics; literature review.

Reference to this paper should be made as follows: Alkan, B., Vera, D.A., Ahmad, M., Ahmad, B. and Harrison, R. (xxxx), 'Complexity in manufacturing systems and its measures: a literature review', European J. Industrial Engineering, Vol. X, No. Y, pp.xxx-Xxx.

Biographical notes: Bugra Alkan received a MSc in Mechanical Engineering from the Izmir Institute of Technology, Izmir, Turkey, in 2012. He is currently pursuing his PhDin Manufacturing Engineering at the Warwick Manufacturing Group (WMG), University of Warwick, UK. His main research interests include 
statistical experimental design, design for manufacturing and assembly, performance optimisation in manufacturing systems, assembly process planning, industrial ergonomics and robotics.

Daniel A. Vera received a MSc in Mechanical and Manufacturing Engineering from the E.N.I. Tarbes, France, in 2000 and the $\mathrm{PhD}$ in Manufacturing Engineering from the Loughborough University, Loughborough, UK, in 2004. His research interests are focused on various aspects of manufacturing from the modelling, analysis, and optimisation of engineering processes to the design and development of 3D-based virtual engineering and collaboration tools for supporting the manufacturing system lifecycle.

Mussawar Ahmad obtained a degree in Mechanical Engineering with Automotive Design from the Brunel University in 2013 and a $\mathrm{PhD}$ in Manufacturing Systems Engineering at the University of Warwick in 2017. He is currently a Manufacturing Systems Engineer at Rolls Royce. His research interests include knowledge-based manufacturing, complexity in manufacturing, as well as the manufacture and assembly of sustainable technologies such as hydrogen fuel cells and automotive battery packs.

Bilal Ahmad received a MSc in Mechatronics and a $\mathrm{PhD}$ in Automation Systems from the Loughborough University, Loughborough, UK, in 2007 and 2014, respectively. He is working as a Research Fellow in the Warwick Manufacturing Group (WMG), University of Warwick, Coventry, UK. His research interests are in the area of virtual modelling and control software engineering of industrial automation systems.

Robert Harrison received a BTech and $\mathrm{PhD}$ in Mechanical and manufacturing Engineering from the Loughborough University, Loughborough, UK, in 1981 and 1991, respectively. $\mathrm{He}$ is a Professor of automation systems in the Warwick Manufacturing Group (WMG), University of Warwick, UK He has been principal investigator on more than 35 industrially oriented European Union, UK Government, and commercial R\&D projects related to manufacturing automation, with current projects focusing on life-cycle engineering and virtual commissioning, control deployment, andaugmented reality in applications including future production systems for batteries, fuel cells, and electric machines. He led the UK research related to Ford's Technology Cycle Plan for power-train manufacturing automation. He was Recipient of a Royal Academy of Engineering Global Research Award to study 'Life-cycle Engineering of Modular Reconfigurable Manufacturing Automation'.

\section{Introduction}

In the last century, the global manufacturing industry has been shaped by various economic, technological and socio-political progresses, socio-environmental regulations, heterogeneity and above all, globalisation of markets and increased competitiveness (ElMaraghy et al., 2012). Consequently, new manufacturing paradigms including increased demand for high-variety production, reduced product life-cycles, and mass customisation have emerged (Efthymiou et al., 2016). This requires manufacturing enterprises to constantly improve their production systems in terms of flexibility, reliability, and responsiveness to satisfy customer demands (Vrabič and Butala, 2011). To meet production 
targets of increasingly complex products with higher quality requirements and reduced time to market, the manufacturing industry employs highly automated production systems composed of numerous sub-systems of various nature, including: machining and processing systems, material handling devices and material storage and retrieval units (Cho et al., 2009). According to ElMaraghy et al. (2012), these advancements and modifications have increased complexity of manufacturing organisations all the way down to the shop floors.

An increase in manufacturing systems complexity was reported to negatively impact all aspects of manufacturing, in terms of: production quality, reliability, throughput and production time, and disturbs the system's efficiency at design, operation, maintenance, and management levels (Schuh et al., 2015). Moreover, complexity and the occurrence of failure within manufacturing systems are tightly coupled (ElMaraghy et al., 2012). An increase in complexity in manufacturing systems is only acceptable if it enhances capabilities, functions, usability, and performance of the system, but should otherwise be eliminated or reduced (Samy and ElMaraghy, 2012). Therefore, complexity and its impact on the system key performance indicators (KPIs) should be identified and quantified to remain profitable and competitive, and to respond rapidly to the volatile markets and rising product variety (Mattsson et al., 2011). In order to achieve this, an analysis and assessment of complexity identifying its impacts is vital (Gotzfried, 2013). This highlights critical managerial aspects, and thus enables the development of strategies to manage system complexity. Figure 1 summarises the existence and evolution of complexity in the manufacturing industry along with its cause-effect relationships.

Figure 1 The existence and evolution of complexity in the manufacturing industry along with its cause-effect relationships (see online version for colours)

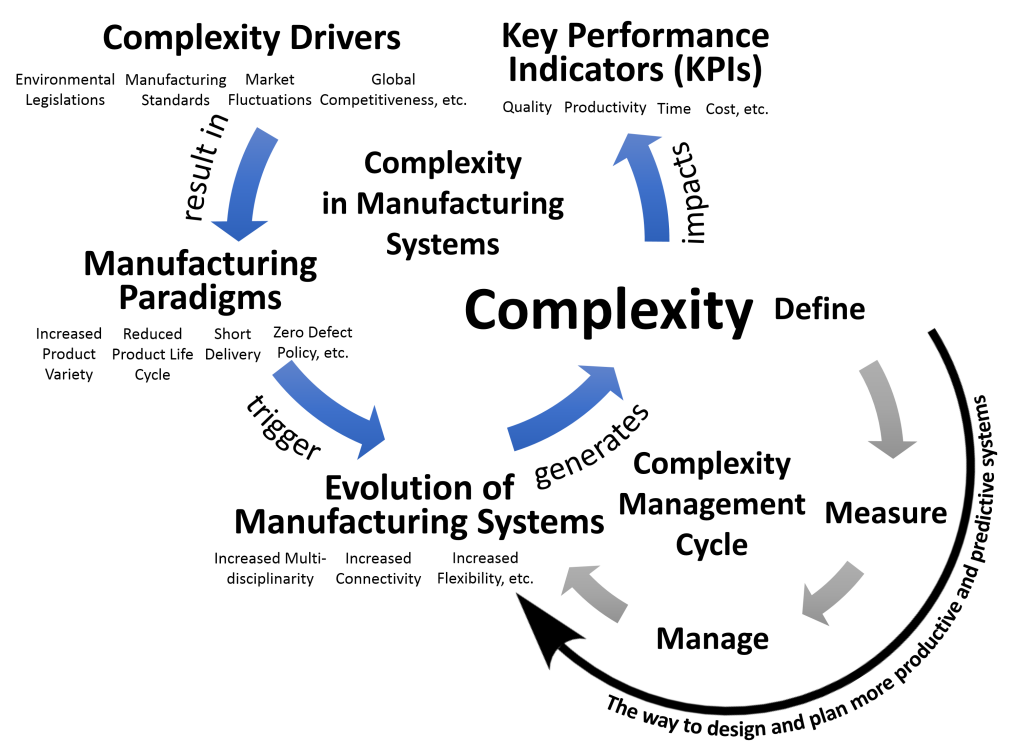


In the literature, several reviews already exist that address the assessment methods and management of complexity in manufacturing. De Toni et al. (2001) is perhaps one of the earliest reviews on manufacturing system complexity and as a consequence of this the review is limited by the knowledge available at the time. More recently ElMaraghy et al. (2012) presented a review however due to its broad scope, a critical cross-evaluation of assessment methods was not present. Finally, Efthymiou et al. (2016) provide a critical review but focus primarily on quantitative assessment methods. This paper addresses the identified shortcomings of existing works by:

1 Consolidating the literature on complexity assessment in manufacturing of the last two decades and cross-evaluating both qualitative and quantitative methods.

2 Based on the trends identified, presents a set of recommendations for the academic community as to how complexity assessment could be addressed to support industrial requirements.

The rest of the paper is organised as follows: Section 2 presents an introduction to the drivers of complexity in manufacturing industry and types of complexity experienced in manufacturing systems. Section 3 reviews the literature and identifies the typical symptoms observed in complex manufacturing systems. Section 4 presents the theoretical foundation of complexity evaluation methods and provides a detailed look on the studies published in the literature. This section also addresses the limitations of the reviewed practices. Finally, a comprehensive outlook for proposed future research directions and conclusion of the paper are presented in Sections 5 and 6, respectively.

\section{Manufacturing systems complexity}

\subsection{Drivers of manufacturing systems complexity}

Modern manufacturing systems work in ambiguous and rapidly changing environment guided by fluctuations in global, socio-political, and economic factors (ElMaraghy et al., 2013). They are directly influenced by the external complexity driven by demand uncertainty and volatility, technological advancements, global competition, and supplier variability (Gotzfried, 2013). These drivers can be associated and linked with the internal complexity in a company, where they are mainly leveraged by factors such as: a high number of heterogeneous customers, large product portfolios, increased product complexity, and a high number and variety of business targets (Marti, 2007). This results in increased uncertainty in manufacturing systems leading to increased information generation and unpredicted/unknown behaviours (ElMaraghy et al., 2013). As an example, product variety necessitates a higher degree of flexibility for handling components due to the variations in the technical and functional aspects of the products such as: shape, size, and configuration (Chinnathai et al., 2017). This results in higher system complexity and costs due to the new or modified equipment that must accommodate the product variety and floor space requirements. Handling demand uncertainty requires the system to react and adapt, resulting in stochastic line balancing problems (Bilge et al., 2015). On the other hand, an increase in demand often requires more sophisticated machine design and more machines as cycle times become the focus of the manufacturing system, thus returning to 
the line balancing problem (Fathi et al., 2016). High quality standards demand additional quality check processes within the manufacturing system, again increasing the number of stations, or even the complexity of a given station such that it can assess process quality. In addition, management, analysis, and appropriate exploitation of quality data all contribute to manufacturing system complexity.

Uncertainty created by the product variety, is also attributed to the complexity of tasks that operators need to carry out which, if not designed correctly, can reach the cognitive and physical limits of humans (Alkan et al., 2016a). A combination of quantitative and qualitative parameters contributes towards operator-system interaction complexity. Quantitative aspects include the length of a sequence, the number of tools that need to be used, ergonomics, clarity of instructions, the quality requirements, and the variety of products that the operator is required to work on (Falck et al., 2014). Qualitative aspects refer to an operator's level of training, expertise and competence, personal factors, such as: culture, background and management strategies ( $\mathrm{Liu}$ and $\mathrm{Li}, 2012$ ). The interactions of these parameters can result in unpredictable behaviour which can be difficult to control (Alkan et al., 2016b).

As manufacturing system functionality increases, so too does the manufacturing control system complexity. This is due to the integration of more modules, communication protocols, and interfaces, i.e., an increase in more dependencies and couplings (Alkan et al., 2017). This, in turn, impacts on the re-usability, modifiability, interpret-ability, and maintenance of the control software (Phukan et al., 2005). Complexity also affects system ramp-up and reconfiguration efficiency. Moreover, complex material flow impacts the shop floor decision making efficiency by disturbing material flow smoothness, lengthening the travel time, creating workstation starvation, and increasing the possibility of bottlenecks and downtime (Huang, 2003). Multi-disciplinarity is a natural result of new manufacturing paradigms, since to satisfy customer demands, products and processes require integration of multiple disciplines. Multi-disciplinary systems typically consist of engineering domains of varied specialisations, e.g., business management, human resources, quality control, stock control, and many more. Although they are considered to be a source of innovation that adds value, they face increase in both complexity and the chance of design failures (Tomiyama et al., 2007). A high level of concurrent engineering facilitated by multi-disciplinarity, dramatically increases both product and product development complexity which in turn impacts the manufacturing system complexity (Tomiyama et al., 2007).

\subsection{Types of complexity}

Complexity in manufacturing systems can be defined within two domains: physical and functional (ElMaraghy et al., 2012) (Figure 2). Complexity in the physical domain is further categorised into two groups: static and dynamic (Frizelle and Woodcock, 1995). Static (or structural) complexity represents time independent characteristics of a manufacturing system and focuses on types of sub-systems and strength of interconnections (Deshmukh, 1998). Dynamic (or operational) complexity represents system's operational characteristics and involves aspects of time and randomness (Frizelle and Suhov, 2001). Dynamic complexity is described as "the expected amount of information required to describe state of a system deviating from its performance expectations due to the unpredictability" (ElMaraghy et al., 2012). 
Figure 2 Classification of complexity types in physical and functional domains (see online version for colours)

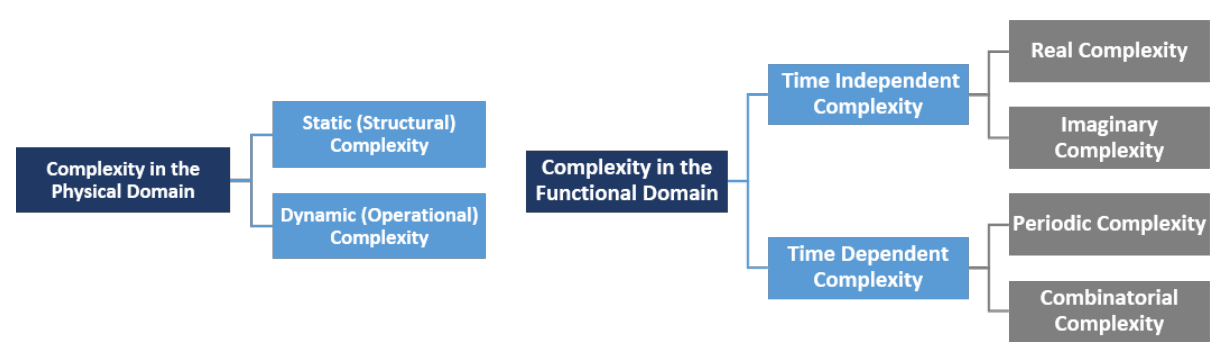

Source: Adapted from ElMaraghy et al. (2012)

Complexity in the functional domain is also classified into two sub-groups: time independent and time dependent (Sun, 2013). It is used to represent emerged uncertainty while the system is performing certain tasks under pre-defined functional requirements (Sun, 2013). Time-independent complexity arises from non-satisfied functional requirements during the system's life cycle due to the factors such as: lack of understanding and/or knowledge about the system or component interactions (Wiendahl and Scholtissek, 1994) and the inability to cope with a large variety of components and interactions. Time-independent complexity is further categorised into real and imaginary. Time-independent real complexity can be considered as the information content, which is a unit of probability of achieving functional requirements (Sun, 2013). Time-independent imaginary complexity is referred to as the unpredictability due to the lack of understanding between functional requirements and design parameters (Lee, 2003). Time dependent complexity may increase with respect to time (Chryssolouris et al., 2013). It arises in the forms of combinatorial and periodic complexity, depending on whether unpredictability grows open-endedly or occasionally stops at a specific point and returns to the initial levels (Sun, 2013).

\section{Symptoms of complex manufacturing systems}

Analysing and understanding manufacturing complexity allows us to develop and implement the correct strategies for management of complexity (Efthymiou et al., 2016). This study assesses publications on manufacturing system complexity through a systematic review. The following databases were scanned: ScienceDirect, IEEExplore, Emerald Insight, ACM Digital Library, Scopus, Springerlink, Web of Science, and Google Scholar. Ninety-three studies that fulfilled the following conditions were further investigated: 
1 Complexity reported in the research must be associated to manufacturing systems or system's KPIs.

2 Study must provide, at least: a theoretical development, extension of a previous approach, a real test case implementation, or an optimisation application.

3 Study must be published in or after 1995.

4 Study must be accessible and offer well-defined and clear information.

Table 1 The symptoms of complex manufacturing systems

\begin{tabular}{ll}
\hline Class of symptoms & Symptoms used in the assessment of manufacturing system complexity \\
\hline Nonlinear behaviours & The existence of repeating patterns observed in the \\
& long-term behaviours. \\
& Sensitivity to the initial demand and production control parameters. \\
& High impact of structural modifications on the \\
& manufacturing performance. \\
Operational uncertainties Increased information content of resource states and & process scheduling queues. \\
& Significant deviations between scheduled and observed resource states. \\
& Uncertainty in handling product variety. \\
& Stochasticity and unpredictability of manufacturing processes \\
& and system KPIs. \\
& Existence of the turbulence in the manufacturing flow. \\
& Increased diversity, quantity and information content of \\
Phystem related elements. & High dependency and interconnectivity between system related elements. \\
Human perceptions & Knowledge complexity \\
& Technological complexity
\end{tabular}

Based on the observations from the literature, different definitions for the conceptualisation of specific aspects of complexity in manufacturing systems have been found. These definitions distinguish manufacturing system complexity based on a number of symptoms to indicate its existence. Accordingly, twelve symptoms that are perceived to be an indication of complexity have been identified (according to existing literature within this domain). These symptoms are then grouped into four classes which have been selected based on the perspective of observation of a given symptom: nonlinear behaviours, operational uncertainties, physical situation and human perceptions, and summarised in Table 1. Table 2 classifies the reviewed studies based on the complexity type, class of symptoms and the theoretical origins of the assessment method used. 
Table 2 Review of the literature on manufacturing system complexity

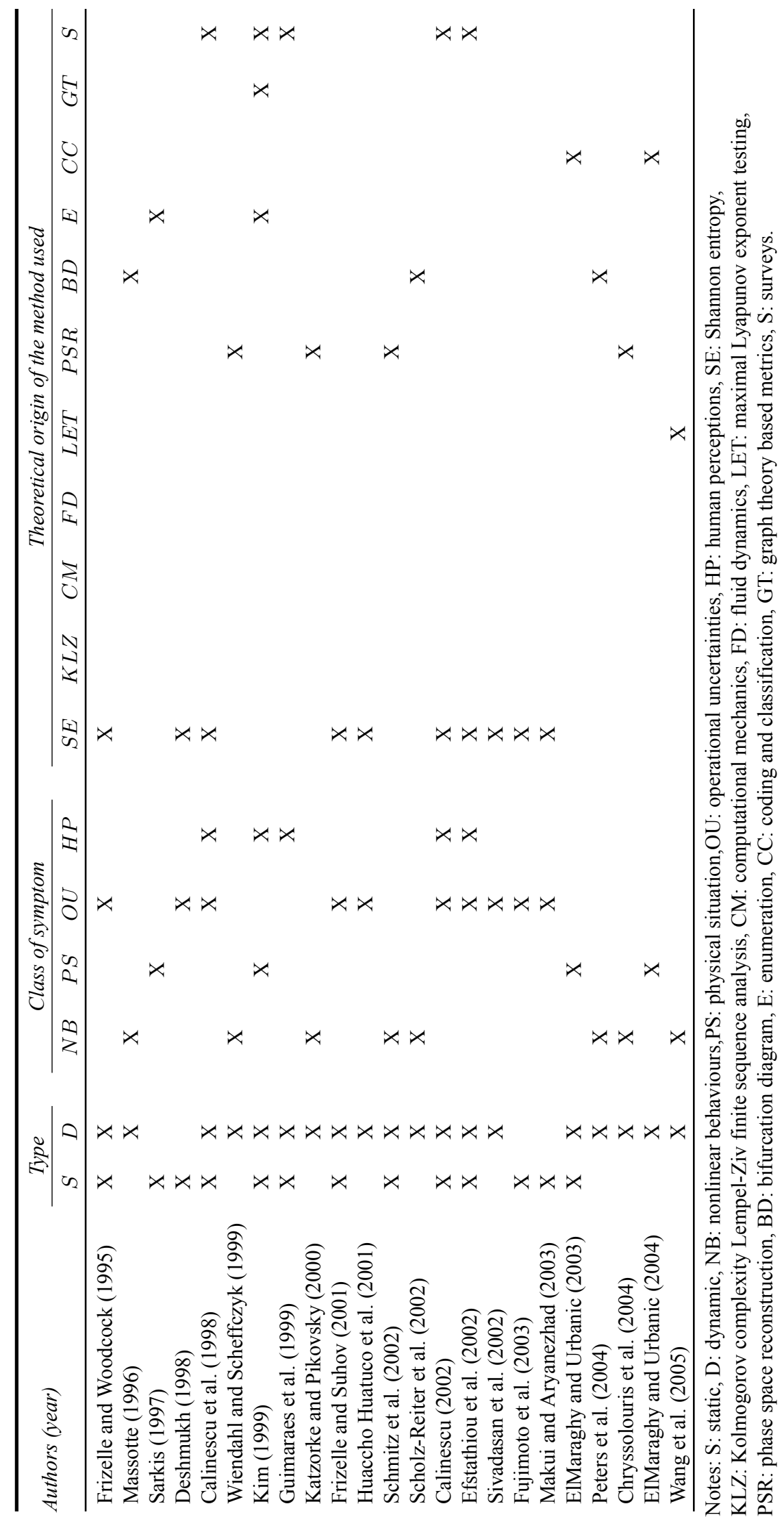


Table 2 Review of the literature on manufacturing system complexity (continued)

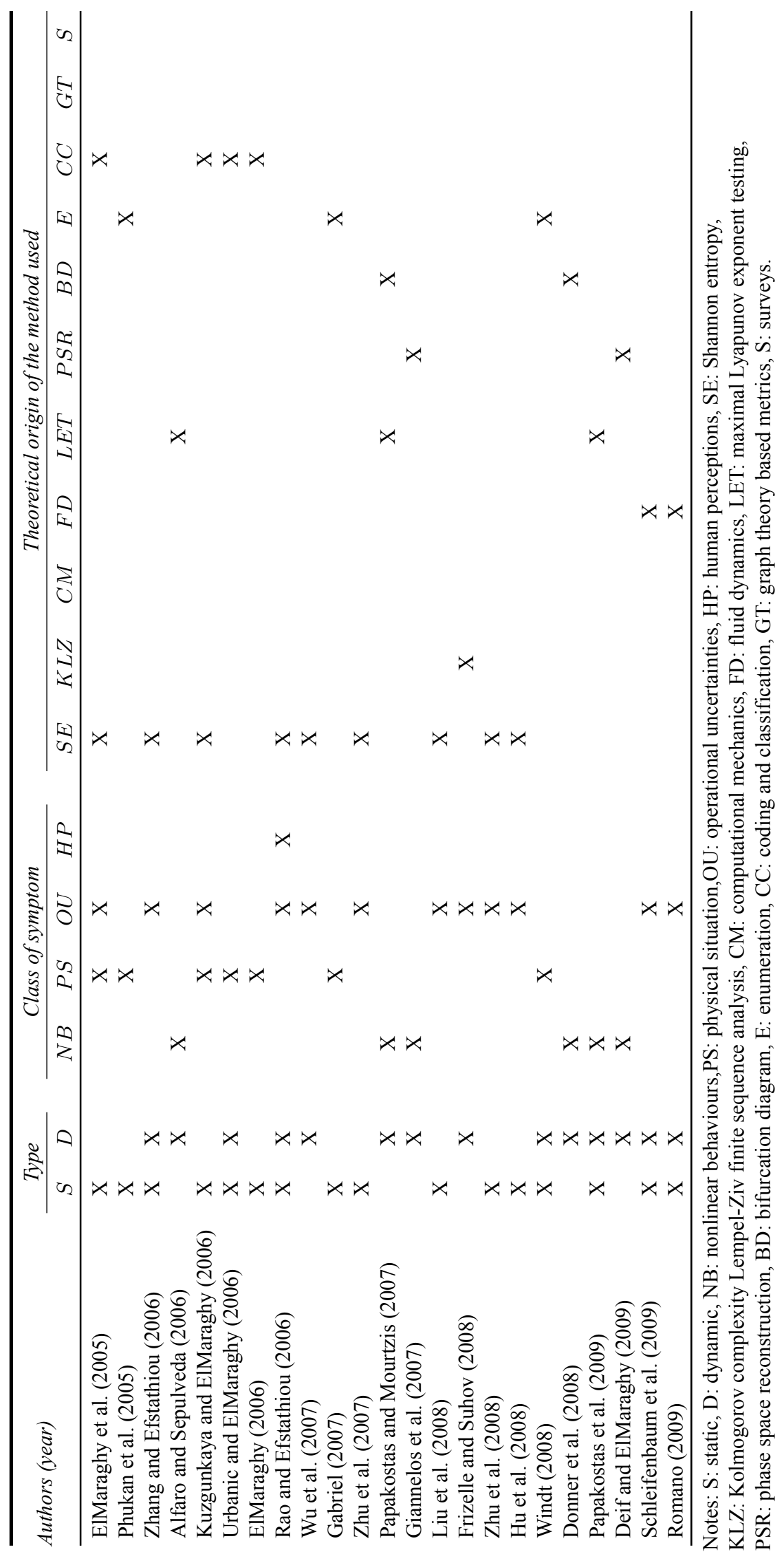




$$
8
$$


Table 2 Review of the literature on manufacturing system complexity (continued)

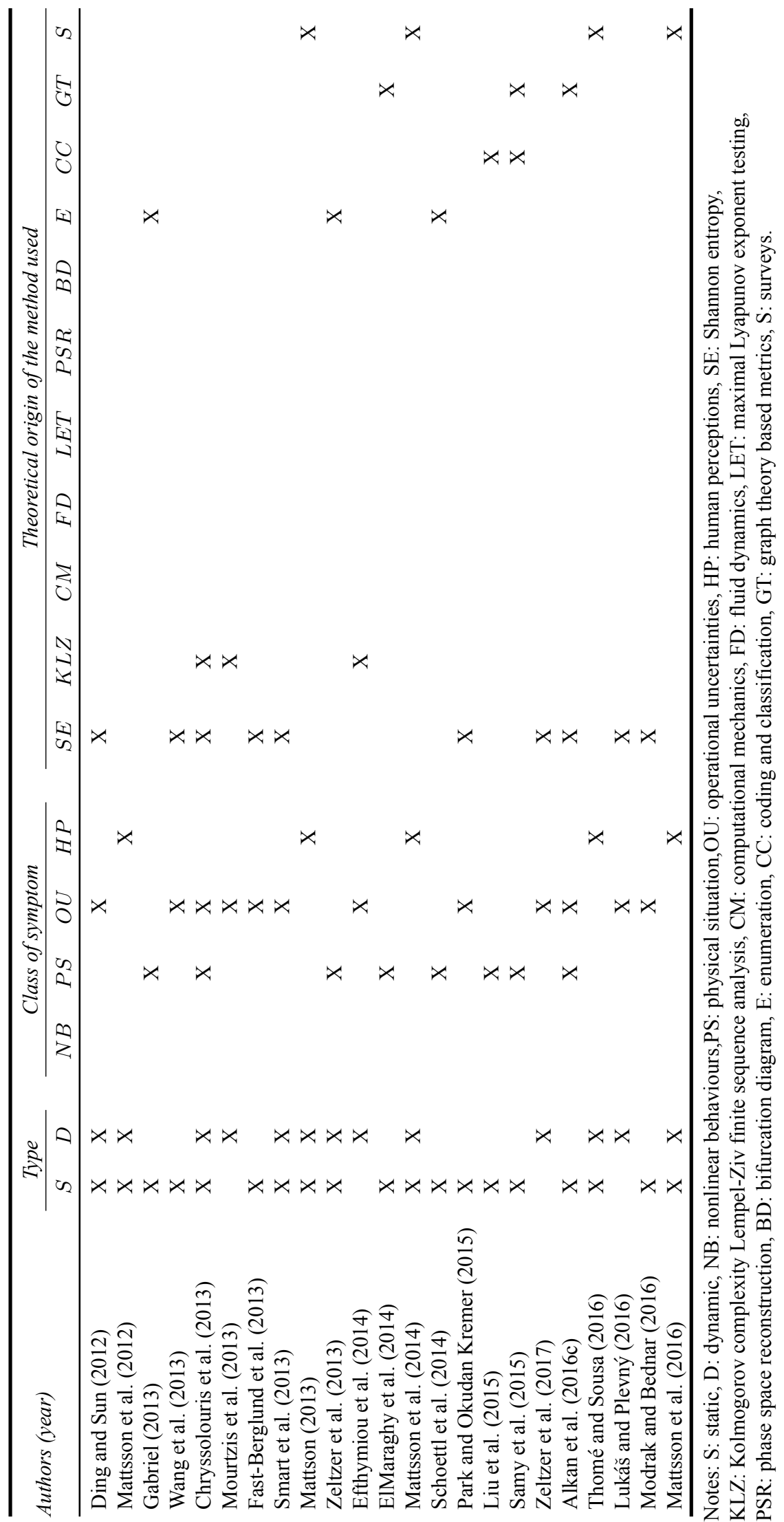




\subsection{Symptoms observed from nonlinear behaviours}

The most typical feature of complex systems is the existence of nonlinear behaviours. In the literature, several studies perceive complexity in the existence of symptoms associated with unstable dynamic phenomena whose identification require scanning of production records over a reasonable time interval. The first symptom in this class, is the existence of repeating patterns observed in the long-term behaviours of production systems. In this context, long-term behaviours indicate the interaction and evolution of dynamic system parameters which are defined by geometrical structures generated through phase space reconstruction methods. This symptom is investigated in the following studies (Chryssolouris et al., 2004; Deif and ElMaraghy, 2009; Donner et al., 2008; Giannelos et al., 2007; Wiendahl and Scheffczyk, 1999; Katzorke and Pikovsky, 2000). The second symptom is the sensitivity to initial conditions. Accordingly, systems exhibiting large deviations in meeting due dates or performance goals by even small changes in initial conditions or production control parameters, such as WIP levels, can be considered as complex. This symptom is a result of both static and dynamic complexity resulting from the factors such as: production delays, multiple-feedback loops and external and internal disturbances, and analysed through the approaches derived from the chaos and nonlinear dynamics theory, such as bifurcation diagrams and maximal Lyapunov exponent testing, in the following studies: (Alfaro and Sepulveda, 2006; Donner et al., 2008; Massotte, 1996; Papakostas and Mourtzis, 2007; Schmitz et al., 2002; Scholz-Reiter et al., 2002; Wang et al., 2005). The third symptom in this class is the dynamic behaviours emerging from the coupling between the intrinsic configuration of the system and uncertainty linked with system's operations. This symptom is a reflection of static complexity occurring due to the structural alterations (e.g., adding/removing equipment) and analysed via bifurcation diagrams and maximal Lyapunov exponent testing in (Papakostas et al., 2009) and (Schmitz et al., 2002), respectively.

\subsection{Symptoms observed via operational uncertainties}

An increase in complexity results in various operational problems including batch-and-queue decision-making inefficiency, lack of process synchronisation, increased lead and ramp-up times, and performance fluctuations (Aqlan et al., 2017). In the literature, a number of symptoms, observed through uncertainties in the operational flow, is employed to perceive manufacturing system complexity. The first symptom in this class is the increased amount of information which is needed to define the scheduled state of the system and its components. This symptom is a reflection of inherent effort of the process for producing the required quantity and kind of products in a certain time interval (Calinescu et al., 2000), and it arises due to the various factors, including: increased number of parts, operations and machines, increased sequence flexibility, and increased resource sharing, etc. In this context, information content is linked to the uncertainty associated with the probability of an entity being in a predefined state. This symptom is a direct result of static complexity and is analysed by means of Shannon entropy in the following studies: (Calinescu, 2002; Deshmukh, 1998; Efstathiou et al., 2002; Frizelle and Suhov, 2008; Frizelle and Woodcock, 1995; Huaccho Huatuco et al., 2001; Liu et al., 2008; Makui and Aryanezhad, 2003; Park and Okudan Kremer, 2015; Zhang and Efstathiou, 2006; Zhang, 2011, 2012). The second symptom is the operational dynamism occurring due to several factors such as: part reject, rework, absenteeism, and resource breakdowns, etc. (Calinescu, 
2002). Accordingly, systems in which it is difficult to monitor their operational status, can be considered as complex (Frizelle and Woodcock, 1995). In this context, complexity is estimated by analysing the deviation between observed and scheduled resource states (in other words, the probability of a resource being out of schedule) which is captured through real-time process observations taken at regular intervals. This symptom is a consequence of dynamic complexity and investigated by means of Shannon entropy in numerous studies (Alfaro and Sepulveda, 2006; Calinescu et al., 1998; Calinescu, 2002; Frizelle and Suhov, 2001; Frizelle and Woodcock, 1995; Huaccho Huatuco et al., 2009; Sivadasan et al., 2010; Smart et al., 2013; Wu et al., 2007; Zhang and Efstathiou, 2006; Zhang, 2011, 2012). The third symptom in this class is the uncertainty in handling increased product variety which is often linked to the risk factors associated with operator's choices of tools, fixtures, and assembly procedures. In this context, complexity is referred as the averaged vagueness in a random process of managing a number of product variants, which depends on the sum of the introduced varieties at a workstation and the conveyed varieties from all the upstream workstations. This symptom, also referred to as the operator choice complexity, is a representation of structural complexity associated with the system configuration topology, and investigated by means of Shannon entropy in the following studies: (Fast-Berglund et al., 2013; Wang and $\mathrm{Hu}, 2010$; Wang, 2010; Wang et al., 2011, 2013; Zhu et al., 2007, 2008; Zhu, 2009). The fourth symptom in this class is the degree of uncertainty associated to the predictability of manufacturing operations and system KPIs. This symptom is a consequence of dynamic complexity occurring due to the factors such as: incompleteness of information, disturbances, and uncertainties inherent to the manufacturing environment, and captured by analysing the prediction efficiency of manufacturing processes (Vrabič and Butala, 2011, 2012) and by analysing unpredictability of manufacturing system KPIs (Chryssolouris et al., 2013; Efthymiou et al., 2014; Mourtzis et al., 2013). The last symptom in this class is the existence of manufacturing flow turbulence arising due to the interactions among system performance, lead time, process structure and manufacturing system configurations. In the literature, this symptom is analysed by employing the concept of Reynold number derived from fluid dynamics analogy in the following studies (Efthymiou et al., 2009; Schleifenbaum et al., 2009; Romano, 2009).

\subsection{Symptoms observed from the physical situation}

Complex system theory describes a complex system as a system that is composed of many components and exhibits hierarchy and self-organisation arising due to the dynamic interaction of its components (Bar-Yam, 1997). From this viewpoint, the third class contains complexity symptoms that can be perceived through analysing system's physical situation:

1 Increased variety, quantity and information content of system elements.

2 The significance of their interrelations and interdependencies.

These symptoms can be searched within the various aspects of the system, e.g., system configuration, material flow patterns, control and information flow patterns, intrinsic process hierarchy, etc., and analysed by means of heuristics including: enumeration and classification and coding, as well as the methods derived from graph theory. Enumeration based approaches try to capture information content of the system by 
counting system-related elements, e.g., resources, products, customer orders, tasks, etc. in a systematic manner (Garbie and Shikdar, 2010; Kim, 1999; Sarkis, 1997; Schoettl et al., 2014; Windt, 2008). In this group, a number of studies also attempted to link complexity to the system performance by correlating the enumerated elements with the real or simulated production data (Gabriel, 2007, 2013; Han et al., 2011; Zeltzer et al., 2013). Classification and coding based approaches, on the other hand, finds the relative importance of each enumerated factors by means of heuristics based classifications (ElMaraghy and Urbanic, 2003; ElMaraghy, 2005; Liu et al., 2015; Samy et al., 2015; Samy and ElMaraghy, 2012; Urbanic and ElMaraghy, 2006). These approaches are also used together with the Shannon entropy to link complexity to the uncertainty related to the information content of resource states (e.g., resource availability) in (ElMaraghy et al., 2005; Kuzgunkaya and ElMaraghy, 2006). In the literature, complexity is also described by the system's information content which is characterised by the connectivity and dependency among various system elements (e.g., material flow connections and dependency within the process hierarchy etc.). These approaches often use methods derived from graph theory and information entropy (e.g., node betweenness centrality, vertex degree, etc.) (Alkan et al., 2016c; ElMaraghy et al., 2014; Espinoza et al., 2012; Maksimović and Petrović, 2009; Samy et al., 2015; Chryssolouris et al., 2013; Modrak et al., 2013; Modrak and Bednar, 2016).

\subsection{Symptoms observed from human perceptions}

Along with its objectivity, complexity also has a subjective nature, making it dependent on the system being considered and the view of the human spectator (Mattson, 2013). In view of that, the last class of symptoms contains complexity indicators which can be perceived by humans. In this class, the symptoms are classified into two sub-groups:

1 Technological complexity indicating the complexity of the underlying technology used to perform system related activities.

2 Knowledge complexity representing the domain-specific knowledge and decision-making complexity.

In the related literature, individual perspectives about manufacturing system complexity are analysed and captured using surveys (i.e., structured and semi-structured questionnaires and interviews) (Calinescu et al., 1998; Calinescu, 2002; Guimaraes et al., 1999; Kim, 1999; Mattsson et al., 2011; Mattson, 2013; Mattsson et al., 2012, 2014, 2016; Thomé and Sousa, 2016).

\section{Methods for assessing complexity in manufacturing systems}

The previous section has identified the symptoms of complexity which exist within several aspects of a manufacturing system. This chapter examines the mentioned assessment and analysis methods for capturing these symptoms. By following a classification scheme mainly based on the taxonomy presented by Efthymiou et al. (2016), these methods are investigated according to respective theoretical origins: 
1 chaos and nonlinear dynamics theory

2 information theory

3 heuristics

4 graph theory

5 fluid dynamics analogy

6 surveys

7 hybrid methods.

Figure 3 shows the complexity symptom-assessment method pairings.

Figure 3 The complexity symptom-assessment method pairings (see online version for colours)

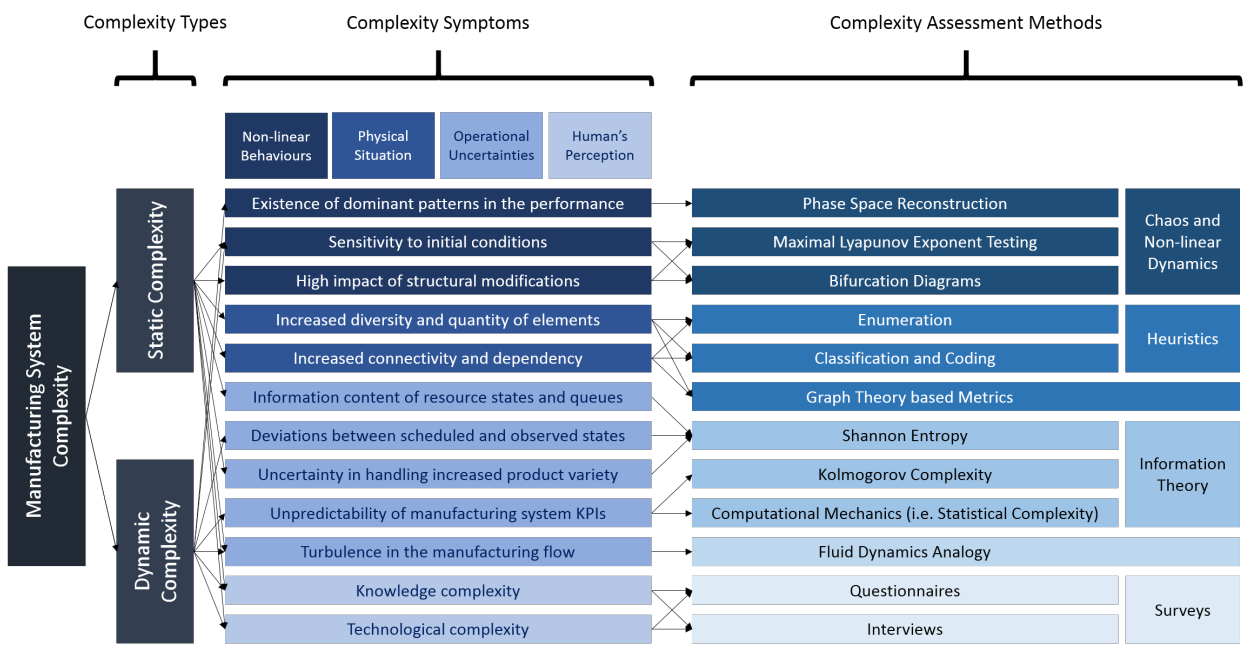

\subsection{Chaos and nonlinear dynamics theory}

Chaos and nonlinear dynamics system theory is a trending mathematical area with increasing interests in the fields of physics, engineering and social sciences. In the literature, the methods derived from chaos and nonlinear dynamics theory are often employed to measure complexity through analysing symptoms connected to the system's dynamic behaviours. These methods include: phase space reconstruction, maximal Lyapunov exponent testing and bifurcation diagrams.

\subsubsection{Phase space reconstruction}

Phase space reconstruction aims to construct the system state through using corresponding historical data and observing it in a higher dimensional space (Rong-Yi and Xiao-Jing, 2011). Reconstruction of a phase space can be done via several different ways, such 
as: phase portraits, Poincare map, recurrence plots and time delay plots. Phase space reconstruction techniques provide a deeper understanding of system behaviours and corresponding factors that contribute towards behavioural changes by offering views of the system in geometric patterns. They have been employed in several studies aiming to analyse nonlinear and unpredictable behaviours of modern production systems. Wiendahl and Scheffczyk (1999) investigated a simple simulated model of a paint-spraying system. The paint thickness of a coating depending on the previous layer of coating and machine parameters such as adjustable spray gun pressure, are investigated. The employed control function was found to cause deterministic chaotic behaviours inducing a unique pattern in the phase space while being undetectable in statistical analyses. Katzorke and Pikovsky (2000) inspected a simple balanced three-funnel model of production dynamics for both continuous and discrete order flows. Peters et al. (2004) examined dynamical behaviours of an idealised manufacturing system subjected to the interaction of scheduling policies and buffer capacity restrictions. Poincare map and bifurcation diagrams were employed in these analyses. Chryssolouris et al. (2004) and Giannelos et al. (2007) studied dynamic behaviours of dispatching rules in a simple manufacturing system using phase portraits and time delay plots, respectively. Donner et al. (2008) studied dynamics of a logistic network consisting of a low number of cooperating manufacturers through discrete event simulations and the recurrence plots phase space reconstruction. Deif and ElMaraghy (2009) adapted system dynamics approach to study the dynamic capacity scalability in multi-stage manufacturing systems associated with the operational complexity of the capacity scaling processes. Complexity was defined as the required effort calculated in terms of magnitude and frequency of the capacity scaling response in dynamic demand.

\subsubsection{Maximal Lyapunov exponent testing}

Maximal Lyapunov exponents testing studies the exponential rate of divergence or convergence of trajectories starting from nearby initial points in phase space and hence, is primarily used to study the sensitivity and dependency of dynamic systems on their initial conditions (Sandri, 1996). Systems that have at least one positive maximal Lyapunov exponent are considered sensitive and chaotic. In the literature, several studies have analysed chaotic and nonlinear behaviours of manufacturing systems using maximal Lyapunov exponents testing. Massotte (1996) examined chaotic behaviours of a simple closed loop system. Wang et al. (2005) proposed a methodology to analyse dynamic behaviours of a system to achieve better lot-sizing decisions. Schmitz et al. (2002) surveyed chaotic behaviours on discrete manufacturing systems. Alfaro and Sepulveda (2006) proposed a step by step methodology to estimate system sensitiveness to initial conditions. Papakostas and Mourtzis (2007) analysed the adaptability of a manufacturing system subjected to demand fluctuations.

\subsubsection{Bifurcation diagrams}

Bifurcation diagrams allow the comprehension of how the long-term behaviours of a system change, as particular variables fluctuate. Due to their ability to capture unstable and unexpected behavioural changes and to identify critical system parameters that lead to an unwanted change in the behaviours, these diagrams are considered an effective methodology and have been implemented in a number of studies that investigate the sensitivity of manufacturing systems' performance on design changes (Papakostas et al., 
2009). Scholz-Reiter et al. (2002) studied irregular behaviours of a production system which was assumed to be a part of more complex facility. A set of possible control methods were suggested which are valid for different levels of WIP by using nonlinear dynamics methods. Papakostas and Mourtzis (2007) investigated the dependence of production rate of a steel production company on specific values of model parameters.

\subsubsection{Limitations of methods derived from chaos and nonlinear dynamics theory}

According to Efthymiou et al. (2016), the methods based on chaos and nonlinear dynamics theory offer valuable understandings of the system behaviours, visualises the effect of system parameters on the key performance indicators, and depicts the sensitivity of the system. However, a set of limitations has been flagged in the related literature. Modern manufacturing systems often exhibit stochastic events (e.g., machine breakdowns) rather than deterministic chaos. However, tools and methods developed based on this theory, are not able to capture and analyse such stochastic events (Efthymiou, 2013). Moreover, only maximal Lyapunov exponents testing provides a quantitative measure for chaos within the manufacturing system, other methodologies are limited and offer only schematic analysis for the dynamic system behaviours (Efthymiou et al., 2012). Furthermore, the approaches used for approximation of the Lyapunov exponents require relatively big datasets and they are highly sensitive to the fluctuations in the external factors such as measurement errors and noise (Efthymiou, 2013). In summary, theory of chaos and nonlinear dynamics can be considered a highly valuable tool in behavioural analysis of manufacturing systems. However, these methods require a costly measurement phase and they are not able to capture stochastic complexity sources, therefore it is still questionable as to whether these tools are a practical solution for real industrial environments.

\subsection{Information theory}

Information theory, principally proposed in Shannon's study of communication theory (please see its revised version in Shannon (2001), considers entropy as the degree of ambiguity associated to the outcomes of a random experiment. In the manufacturing domain, this approach is used to capture the following symptoms:

1 Scheduling and observation based information content of resource or queue states.

2 Deviation between scheduled and actual states of the resources.

3 Uncertainty in handling product variety with the context of risk factors related to the operator choices.

4 Unpredictability of manufacturing processes and manufacturing performance indicators.

\subsubsection{Shannon entropy}

In manufacturing domain, Shannon entropy is used to quantify the uncertainty of identifying the required information to define the state of a manufacturing system or its components. In this context, states of resources can be defined subjectively (e.g., busy, 
idle and breakdown, etc.). The probability of states can be measured based on scheduling information (static complexity) and real time observations (dynamic complexity). Frizelle and Woodcock (1995) used Shannon entropy to optimise operation strategies of a manufacturing enterprise. Static complexity was measured through focusing chiefly on queue lengths, whereas dynamic complexity was calculated based on observed states of manufacturing resources (i.e., idle, busy or failed). Deshmukh (1998) enumerated the factors affecting the static complexity of a manufacturing system to define a static complexity metric related to processing requirements and machine capabilities. In the paper, the variation in static complexity was investigated in terms of part resemblance, system volume and product design alterations. Frizelle and Suhov (2001) proposed an entropic complexity measurement to assess the rate of variety in queueing systems and networks by employing Kolmogorov-Sinai entropy. Calinescu et al. (1998) proposed a comparison between entropy and questionnaire based complexity assessment measures. The proposed entropy measure accounted for the following factors: product structure, the structure of shop or plant, planning and scheduling functions, information flow and dynamism, and variability and uncertainty of environment. Efstathiou et al. (2002) presented an expert system to evaluate the decision-making complexity of system-organisation interactions that used existing company data to compute complexity and offer recommendations. Frizelle and Suhov (2008) developed a method to assess dynamic complexity by evaluating the evolution of manufacturing queueing lengths and resource state conditions in three different case studies.

Shannon entropy is also used to measure complexity related to the deviations between scheduled and observed resource states. Huaccho Huatuco et al. (2001) investigated scheduling complexity in a bottle supplier enterprise. Dynamic complexity was assessed by estimating conditional probabilities associated with deviating scheduling states and it was found that complexity can be varied with both customer demand changes and organisational flexibility. Sivadasan et al. (2002) proposed a metric for supplier-customer networks based on the uncertainty of material and information. This metric is then extended and validated in (Sivadasan et al., 2006). Wu et al. (2007) surveyed the relationship between operational complexity and inventory costs. Huaccho Huatuco et al. (2009) proposed a comparison between five different rescheduling strategies based on their effectiveness in reducing complexity that arises due to stochastic machine breakdowns. A series of simulations were performed for this purpose which accounted for: overall information content, variations between schedules, and mean flow time. Reducing unbalanced machine workloads and using low disruption strategies were suggested to reduce operational complexity. Sivadasan et al. (2010) examined the relationship between networks of customers and suppliers, and operational complexity (e.g., scheduling variations). An increase in the operational complexity was found to have a significant association with the reduction in the supplier's inventory capacity. It was suggested that operational complexity could be better managed by incorporating: IT systems, shorter scheduling planning and more frequent information exchanges.

Another implementation of Shannon entropy focuses on the assessment of the uncertainty in handling increased product variety associated with the risk factors related to the operator choices. Fujimoto et al. (2003) developed an information theoretic method to interpret product variety induced complexity arising at the different stages of assembly system by utilising weighted Shannon entropy. In each assembly station, information entropy was assumed to originate from two kind of aspects: 
1 variety flowing through a station

2 product varieties adding in the station.

Zhang and Efstathiou (2006) proposed a complexity metric based on the Shannon entropy for mass customisation in manufacturing systems. The authors pointed out that complexity arises from inventory management primarily influenced by the number of stock locations and the number of product variants that are stored in these areas. Zhu et al. (2007) introduced a measure called 'operator choice complexity' to pursue optimal assembly sequences in mixed-model assembly lines by reducing process sequence complexity which in turn reduced system complexity. Zhu et al. (2008) surveyed operator choice complexity by consolidating product mix and process information in mixed model assembly systems, and provided guidelines for managing complexity at the design phase of such systems. Cho et al. (2009) developed a quantitative complexity assessment approach for various configurations of assembly and disassembly stations. The proposed approach uses probability distribution of information associated with the part processing times, part mix ratios and routings. Wang and $\mathrm{Hu}$ (2010) investigated the relationship between system throughput and complexity associated with human related factors such as operator reaction time and fatigue effects. According to the findings, product variety induced complexity affects the reliability rate of manufacturing stations and disturbs a station's throughput. Hu et al. (2008) proposed a measure for complexity of both assembly systems and their supply chains. Wang et al. (2011) carried out an optimisation study focusing on the relation between product variation and complexity in semi-automatic assembly systems. In this study, a novel measure called relative complexity based on a theoretical model (Makui and Aryanezhad, 2003) was developed to find out the optimal set of variants to enlarge the market share while reducing complexity. Wang et al. (2013) extended the previous complexity model (Wang et al., 2011) and carried out an optimisation study focusing on the configurations of the mixed model assembly systems.

\subsubsection{Kolmogorov complexity and Lempel-Ziv analysis of finite time series}

Kolmogorov complexity is an application of the algorithmic information theory in computer science, named after Andrey Kolmogorov who first presented this subject in 1963. According to Kolmogorov's idea, the complexity of any binary string is the size of the smallest binary computer program that can reproduce this string on the universal turing machine and then halt (Ming and Vitányi, 2014). Lempel-Ziv complexity metric (Lempel and Ziv, 1976), on the other hand, is a non-parametric scale of finite sequences and it has been used in several applications, including coding and lossless data compression. This metric is presented based on Kolmogorov's axioms and it is associated to the quantity of diverse sub-strings and the proportion of their existence along a given sequence (Efthymiou et al., 2014). In recent years, this metric has been applied to manufacturing systems and manufacturing supply networks to evaluate the irregularity of manufacturing KPIs (Chryssolouris et al., 2013; Efthymiou et al., 2014; Mourtzis et al., 2013). One of the pioneer works presented by Efthymiou et al. (2014), investigated the unpredictability of performance indicators in manufacturing systems. In the study, the fluctuations in the performance time series of critical manufacturing indicators generated through discrete event simulations, were studied by employing Lempel-Ziv complexity measure, then an overall complexity indicator was calculated through assessing weighted average Lempel-Ziv complexity. 


\subsubsection{Computational mechanics}

Computational mechanics concerns the issues of pattern, structure, and organisation and producing a model of a hidden process generated from observed behaviours (Shalizi and Crutchfield, 2001). This approach offers an information-theoretic methodology to find optimal causal models of stochastic processes. Vrabič and Butala (2011) chiefly adopted this approach in manufacturing systems by employing an information theoretic measure to assess prediction efficiency of manufacturing processes. In the work, complexity was represented by statistical complexity, defined as the quantity of historical memory collected during the past processes. This approach differs from other entropy based measures as it relates unpredictability with complexity.

\subsubsection{Limitations of information-theoretic measures}

Information theoretic measures propose an objective way for quantifying both static and dynamic complexity of manufacturing systems. Nevertheless, a set of problems bound back the applicability of the information theory. According to Efthymiou et al. (2016), information theoretic measures are insufficient to link complexity with the manufacturing system performance. Moreover, information theoretic complexity measures provide a single complexity value which provides an insufficient level of granularity to determine where efforts should be focused to make improvements. On the other hand, information theory includes two essential assumptions which may be critical in terms of accuracy. Kim (1999) explains the first assumption as; "complexity is a universal quality that exists, to some degree in all objects, and there is a uniform metric for measuring the complexity of a system”. Klir (1985) argued this statement and stated that describing the complexity as an inherent attribute of an object is not purposeful from an operational point of view. The other assumption states that variables of a system are considered independent. According to the researchers (Badrous, 2011; ElMaraghy, 2005; ElMaraghy et al., 2012), this assumption is not true for real systems which limits the applicability and accuracy of the approach. Similarly, Kim (1999) and ElMaraghy et al. (2012) pointed out that information theory complicates measurement for large systems and assumption of validity of independent states should be replaced with the conditional entropy approach. Furthermore, as there is a subjectivity associated with the selection of resource and queue states, information theoretic measures may struggle to explain perceived complexity, e.g., interactions between human and machine. Issues to be addressed in information theory, include the impact of defective information, measurement cost for dynamic complexity assessment, conversion of the results into meaningful information, and recommendations for issues on manufacturing system design and management (Alkan et al., 2016c). According to Smart et al. (2013), accuracy in probability estimation, interdependency assumption, sample quality and long data recording are the most important factors to be taken care of for those who start out to gather data for measuring structural and operational complexity based on entropic approach. Moreover, further investigation is still required to enhance the predictive capabilities of the information theoretic measures. As an example, Kolmogorov complexity Lempel-Ziv analysis method heavily depended on the observed performance time series length (Efthymiou et al., 2014). Also, this approach require a common time series length for the comparison of dynamic complexity of different manufacturing systems, which may not be the case in many situations (Efthymiou et al., 2016). Computational mechanics approach, 
on the other hand, suffers in terms of practicality, as it requires relatively big amount of data necessary to analyse dynamic complexity.

\subsection{Heuristics}

Heuristics based complexity assessment approaches are close to industrial practice where they attempt to capture the overall information content of a production system using user-subjective or counting based information collection techniques. These methods can be a valuable solution when data availability is limited, i.e., very early design stages.

\subsubsection{Enumeration}

Approaches using enumeration relate complexity to the number of system, product and process related elements, such as: quantity and diversity of resources and manufacturing tasks as well as the number of demand changes. Sarkis (1997), studied the relationship between complexity and productivity of a flexible manufacturing system (FMS). In the study, complexity is considered as the summation of the total number of installed industrial robots and numerically controlled machines. According to the results, a continuous drop in productivity performance is observed as the system's complexity increases. This is attributed to an increase in the number of devices, which correspondingly increases the required efforts (i.e., scheduling and transportation) to operate these devices, which in turn dramatically impacts the efficiency of the system. Kim (1999) studied the effects of product variety over system complexity by proposing a set of metrics consisting of three dynamic and static complexity sources:

1 Relationships between system components described as the quantity of flow paths, number of crossings in the flow paths, cumulative part travel distance, number of combinations of product and machine match.

2 Inherent properties of system components, such as: number of elementary system components and complexity of each elementary component.

3 People related issues, such as: process improvements, information accessibility, number of suggestions, etc.

Gabriel (2007) proposed a static complexity measure called internal static manufacturing complexity (ISMC). The ISMC is designed as a function of distinct number of manufactured components, number of work centres, the volume of production, and the commonality between different product routes. Another enumeration methodology, the complexity cube, is a vector based complexity assessment approach developed by Windt (2008).

\subsubsection{Coding and classification}

The research group at the University of Windsor, Canada has proposed a coding and classification system which aims at quantifying time-independent complexity based on assessing the key aspects of manufacturing systems. ElMaraghy and Urbanic (2003) considered complexity as a combination of three key factors: 
1 the absolute amount of information

2 the variety of information

3 the information content linked to the exertion required to manufacture a machining feature of a product.

Product complexity is represented by the product complexity index, which is calculated by counting different design parameters such as; quantity of features, quantity of inspection checks and diversity of part elements, etc. Process complexity is defined as a function of the product design, the volume requirements, planning horizon and the work environment. The proposed methodology can, according to its authors, be used in any design situation through selection of the suitable facets of the main product and process elements. The original approach was extended by Urbanic and ElMaraghy (2006), to cover complexity in manual manufacturing operations by taking some facets of cognitive complexity related to operator perception into account. Furthermore, ElMaraghy et al. (2005) developed an indices based method for manufacturing systems that utilises heuristics and information theory in which availability of each component is taken into consideration. The metric consists of different complexity fields representing inherent structural and operational characteristics of classes of entities, such as: machines, buffers, material handling systems (MHS) and operators. Later, Kuzgunkaya and ElMaraghy (2006) adapted a hybrid approach to evaluate configuration complexity of reconfigurable manufacturing systems and developed a new measure. The proposed metric is calculated based on information theory, where the state probabilities are defined based on the reliability of different system modules, such as: machines, buffers and MHS. ElMaraghy et al. (2010) and further Samy and ElMaraghy (2012), extended the original classification and coding approach to include assembly oriented static complexity sources of various manufacturing system resources, including machines, buffers and MHSs.

\subsubsection{Limitations of heuristics based approaches}

Due to their subjective nature, heuristics based approaches provide a weaker vision of manufacturing system complexity and they are unable to analyse complicated connections within a system (ElMaraghy et al., 2012). These metrics are heavily dependent on the industrial domain or specific focus that they are designed for, thus, the applicability of heuristics based approaches over different types of production systems and focuses is often limited. In conclusion, heuristics based approaches provide an intuitive view regarding complexity associated with the physical situation, however, due to its subjective nature, it is debatable as to whether these measures reflect overall system complexity accurately.

\subsection{Graph theory based metrics}

Graph theory provides a basis for investigating the entities and their relationships within a system (Kreimeyer, 2009). In recent years, a number of works (Alkan et al., 2016c; Chryssolouris et al., 2013; Jenab and Liu, 2010; ElMaraghy et al., 2014) that have direct and indirect utilisation of the graph and network theory in the assessment of physical aspects of manufacturing system complexity, have been proposed. Chryssolouris et al. (2013) proposed a complexity measure called network complexity, in which graph theory is used to produce adjacency matrix which represents the connection between product, process, 
and resource domains. The vertex degree is then used to assess the coupling between these domains. ElMaraghy et al. (2014) developed a complexity model based on the graph theory which incorporates information content of the system represented by characteristics of its layout.

\subsection{Fluid dynamics analogy}

The fluid dynamics analogy in the manufacturing domain is an analytical framework which has been used previously in modelling of system performance indicators and management of scheduling issues (Avram et al., 1995; Dai, 1995; Weiss, 1999). In manufacturing systems, the fluid dynamics analogy is chiefly used to analyse manufacturing flow turbulence. Efthymiou et al. (2009) used this analogy as a theoretical background and introduced the Reynold number concept to manufacturing systems which aims to identify the transition regime between steady and turbulent manufacturing operations in different work-flow conditions. Moreover, similar Reynold number concepts have been used in assessing complexity in manufacturing systems (Schleifenbaum et al., 2009) and supply chains (Romano, 2009). Although, fluid dynamics analogy can be considered as a promising approach for detection of critical areas that contribute to turbulence in production, it is still a premature practice and requires further investigations (Efthymiou et al., 2016).

\subsection{Surveys}

In the literature, there are a number of papers focusing on both manufacturing system complexity and complexity arising due to user-system interactions by employing structured questionnaires and interviews. Calinescu et al. (1998) proposed a metric based on Meyer and Foley Curley's management of software development framework described in Meyer and Curley (1995). Data used in this study is gathered by questionnaires at different levels of hierarchy within the selected company. Mattsson et al. (2011) developed a questionnaire based complexity index, namely: $C X I$, where users assess production complexity, subjectively. Questionnaire parameters are categorised into five main groups: product/variants, process methods, station layout, equipment, and organisation and environment complexity sources. Falck et al. (2012) proposed an assessment model for assembly task complexity based on the interview study suggesting criteria to identify both low and high assembly complexity. The grade of fulfilment of the aforementioned criteria is used to reflect the degree of production complexity. A similar study which is proposed by Mattson (2013), aims to define manufacturing complexity based on a series of structured interviews in which, subjective opinions of human workers regarding product variants, work content, layout, tools and work instructions are collected. Questionnaires, surveys and interviews attempt to provide insights on how humans perceive manufacturing systems during their life-cycle. They can be used to analyse bottlenecks and to get indications of potential improvements by flagging the interrelating complexity concerns. Although, survey based approaches can capture the perceived level of complexity, these approaches cannot be used in the evaluation of system designs since no physical mock-up or process trials are available. Also, they are limited to questionnaire-stage and their results are dependent on the subjective interpretation of the interviewees. 


\section{Proposed future research directions}

The literature review shows an increase in the total number of articles published per year [Figure 4(a)]; it indicates a growing trend for management and optimisation of complexity in manufacturing systems. This can again be inferred from Figure 4(b), that in the last decade, the number of published studies that discuss about complexity evaluation have increased by more than half when compared to the previous decade. It can be seen from Figure 4(c), that the importance given by academic community to static and dynamic complexity is almost equal, however, the slight increase in the focus on static complexity could be attributed to the fact that it is relatively easier to identify and assess static complexity. Additionally, it is discernible from Figure 4(d), that almost half of the publications investigate complexity symptoms associated with operational uncertainties. This signifies the increased attention given to operational efficiency in scheduling and planning, and shop floor decision-making in comparison to the other classes of symptoms. It is also important to note, studies perceiving complexity through system's physical situation also gained a significant increase. This indicates the importance of proactive evaluation of system designs at the conceptual and preliminary design phases. Also, the popularity of employed methodologies is given in Figure 4(e).

The primary reason for evaluating the complexity of manufacturing systems is to design and build systems that are diagnosable, predictable and productive. These traits translate directly into reduced costs due to ease of maintenance, foresight and efficient use of resources. This paper has presented studies that have been published over the last two decades that offer methodologies for measuring complexity. Approaches that examine complexity during the operational phase of manufacturing systems are often costly; they require large datasets collected by on-site observations and analysed using expert systems. On the other hand, approaches (i.e., heuristics based approaches) that measure complexity from the physical situation of manufacturing systems are less successful as the large amounts of data required are not available at this point of a system's life-cycle. As a result, an assessment of complexity cannot, and thus is not, typically made in industry at the design phase as managers and other key stakeholders require practical efficient methods for measurement, which are simply not available to them (Gabriel, 2007). Furthermore, it has been observed that more is learnt about a given system during the process of measuring complexity than the analysis of the resulting data (Calinescu et al., 1998). This demonstrates two shortcomings of complexity measurement:

1 A disconnect between complexity science and real manufacturing systems means that models are usually unable to evaluate the system at the required level of abstraction, requiring reformulation and thus resulting in non-systemic approaches.

2 Complexity is measured when the system exists in the physical domain, and thus any measurement or assessment can only have a limited impact for making improvements. 
Figure 4 Summary of the literature review: (a) the number of published studies per year (from 1995 to 2016) (b) the number of published studies between the time periods of 1995-2005 and 1996-2006 (c) the popularity of complexity type studied: static (0.7312 per study) and dynamic ( 0.6129 per study) (d) the popularity of class of symptoms studied: operational uncertainties ( 0.5376 per study), dynamic behaviours $(0.1505$ per study), physical situation ( 0.2688 per study), human perspectives $(0.1290$ per study) (e) the popularity of the method employed: Shannon entropy ( 0.4409 per study), Kolmogorov Lempel-Ziv ( 0.0538 per study), computational mechanics $(0.0215$ per study), fluid dynamics ( 0.0323 per study), maximal Lyapunov exponent $(0.0538$ per study), phase space reconstruction ( 0.0645 per study), bifurcation diagrams $(0.0430$ per study), enumeration ( 0.1075 per study), classification and coding ( 0.0860 per study), graph theory ( 0.0645 per study), surveys $(0.1290$ per study) (see online version for colours)

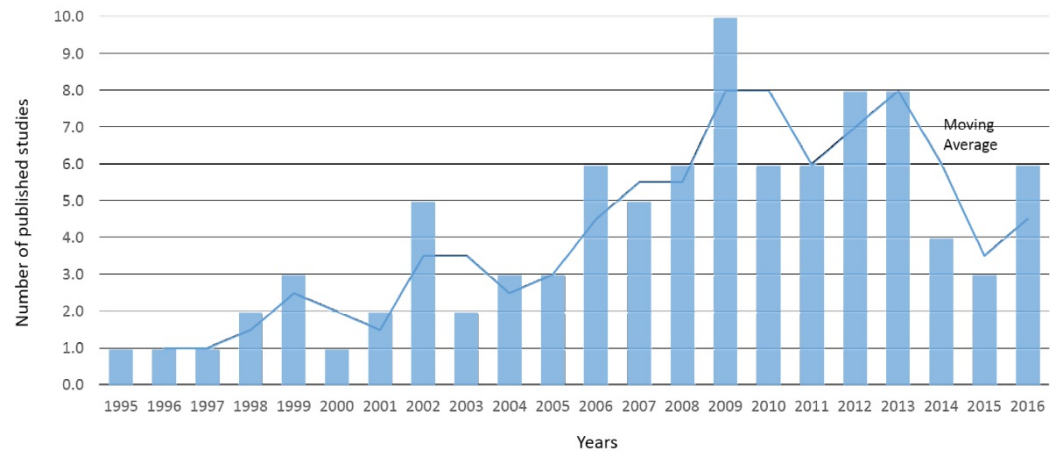

(a)

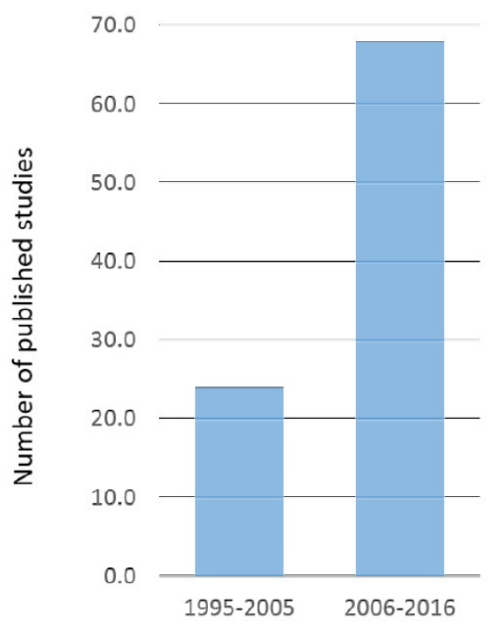

(b)

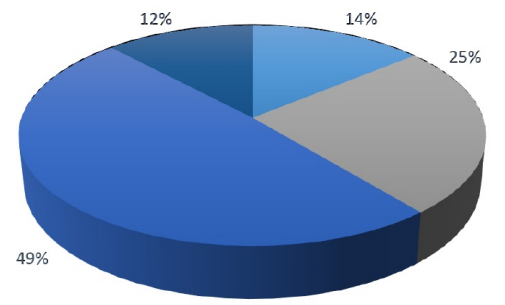

[ Non-linear Behaviours

— Physical Situation

- Operational Uncertainties

(d)

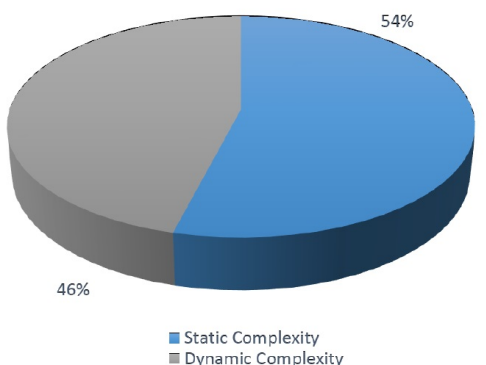

(c)

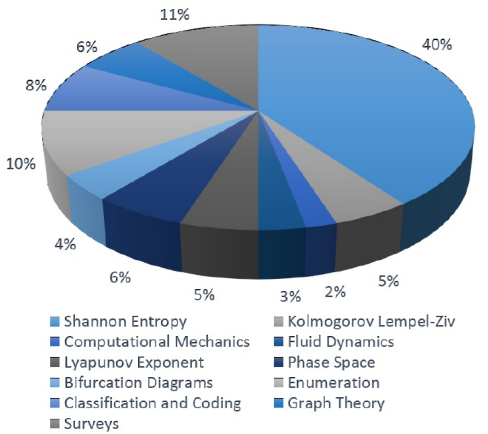

(e) 
In addition, many researchers have offered measurements that provide a single value of complexity for an entire system. However, a manufacturing system is a combination of multiple sub-systems such as: mechanical, electrical, and control as well as process types including: manual, semi-automatic and fully-automatic. Thus, models that can decompose these concepts systematically and capture the data, can accurately measure the complexity of the system and the sub-systems identifying the source of complexity in the system and thus focussed efforts for optimisation.

The classical approach to engineering and design in industry has been heavily reliant either on documents or the minds of designers, engineers and integrators. The paradigm of model-based engineering (MBE) and data driven approaches has emerged in the last decade as a direct result of increased computing power at lower costs. In fact, this is one of the key paradigms of Industry 4.0, although such approaches have been in use before this term was coined. MBE moves the record of authority from documents to digital models allowing engineering teams to more readily understand design change impacts, communicate design intent and analyse a system's design. However, within the context of complexity assessment there remain a number of shortcomings of the existing model-based approach to system's engineering. Firstly, models are not integrated effectively beyond their respective phase or engineering domain. This has the consequence that there is limited transparency as to what impact change would have outside of a given life-cycle phase resulting in unexpected outcomes, a condition inherent of complex systems. Furthermore, the limited transparency beyond a given engineering domain, e.g., electrical vs. mechanical, has a similar consequence. Secondly, the software tools associated with design and engineering have little to no complexity assessment capabilities within them. As has already been mentioned, this is not used by industry as an indicator to infer that perhaps costs and lead-times may increase, or if indeed the complexity is required, then management and control strategies need to be deployed ahead of time. The first shortcoming identified ties in with the second in that if a given engineering tool software developer was to take the first step in having a complexity assessment tool built in, there would be limited value as it would have trouble translating to adjacent and downstream engineering models. As a consequence of these shortcomings, the complexity measurement process in industry remains tedious, time consuming, and generally non-value adding.

Virtual engineering tools are producing vast amounts of datasets which, if streamlined and integrated, can be used as an input to complexity models. Furthermore, virtual engineering tools, whereby the data structure is extendible, allows additional factors to be modelled as more complexity sources are identified and linked. This approach to complexity measurement has two important benefits over the methodologies presented in the literature:

1 An assessment of complexity can be made during the design phase so that those designs deemed excessively complex can be flagged and optimised.

2 The measurement of complexity is automated and integrated within the virtual engineering tools (or in the case of the cyber-physical systems, data is fed directly from the machine's operation) through to the complexity model resulting in reduced measurement efforts.

It is important to note however that fully objective approaches to complexity measurement are not always entirely practical. As a result, approaches such as surveys and questionnaires, 
while they are susceptible to the subjectivity of those questioned, still offer valuable information and such methods can be improved if they follow a systematic approach.

\section{Conclusions}

The objectives of this paper were threefold. This section examines the outcomes of those objectives and what conclusions the authors draw from them.

Firstly, the authors identified a need to produce a critical review of complexity assessment methods for manufacturing systems to address its expected rise as industry enters the fourth industrial revolution. Accordingly, this work has presented:

1 A taxonomy which is comprehensive and captures all complexity assessment methodologies that the authors have been able to identify from a structured literature review.

2 A classification of complexity symptoms into four groups that are mapped to assessment methods.

The conclusion drawn from this part of the work is that there are many methods and there is limited work that addresses how they can be linked to specific industrial needs. Furthermore, industrial methods used to assess complexity today are not accurate, being largely subjective and not systemic. Therefore, the authors argue that there is a need to educate industrial practitioners on the methods available for complexity assessment based on symptoms observed within an organisation.

The second objective of the work revolved around identifying how assessment methods could be linked to different phases of the engineering life-cycle of a production system. At different phases, different types of data exist at different levels of granularity and maturity. However, despite the links proposed by the authors, it is concluded that the cultivation of complexity experts within industry is an important facilitator of assessment. To determine both the engineering data available at a given life-cycle phase and the appropriate complexity assessment method is difficult to encode within rules or best practice because this remains unclear resulting in uncertainty during method selection. Due to the relatively recent emergence of complexity assessment in industry, such activities need to be supported through appropriate tools and methods highlighting a clear direction for engineering software tool developers.

The final objective of this work was to synthesise literature of the last two decades that addressed complexity assessment in manufacturing into a single, referenceable table for complexity assessment practitioners that exist both within industrial and academic environments. The consolidated data was analysed for trends which found that there is a:

1 Growing trend for complexity management and optimisation in manufacturing systems.

2 Heavy focus on complexity assessment associated with operational uncertainties.

In summary, the measurement or assessment of complexity is driven by identifying that a system is complex based on a set of symptoms. The appropriate assessment method is 
selected based on the data available often aligned to an engineering phase. Appropriate and correct execution of an assessment method is derived from referencing a synthesis of the literature of the last two decades within the domain. Ultimately, assessment is an important phase in the complexity life-cycle so that critical design parameters of manufacturing systems can be analysed, verified and optimised. However, correct and accurate assessment is not present within industry and thus it is the role of academics to transform complexity from a scientific exercise to something that can be practiced and administered by industry.

\section{Acknowledgements}

This study is supported by UK EPSRC through Knowledge Driven Configurable Manufacturing (KDCM) research project and by Turkey's Ministry of National Education's Post-Graduate Scholarship.

\section{References}

Abad, A.G. (2010) Modeling and Analysis of Process Complexity and Performance in Mixed Model Assembly Systems, PhD thesis, University of Michigan.

Abad, A.G. and Jin, J. (2011) 'Complexity metrics for mixed model manufacturing systems based on information entropy', Int. J. Information and Decision Sciences, Vol. 3, No. 4, pp.313-334.

Alfaro, M.D. and Sepulveda, J.M. (2006) 'Chaotic behavior in manufacturing systems', International Journal of Production Economics, Vol. 101, No. 1, pp.150-158.

Alkan, B., Vera, D., Ahmad, M., Ahmad, B. and Harrison, R. (2016a) 'A lightweight approach for human factor assessment in virtual assembly designs: an evaluation model for postural risk and metabolic workload', Procedia CIRP, Vol. 44, pp.26-31.

Alkan, B., Vera, D., Ahmad, M., Ahmad, B. and Harrison, R. (2016b) 'A model for complexity assessment in manual assembly operations through predetermined motion time systems', Procedia CIRP, Vol. 44, pp.429-434.

Alkan, B., Vera, D., Ahmad, M., Ahmad, B. and Harrison, R. (2016c) 'Design evaluation of automated manufacturing processes based on complexity of control logic', 26th CIRP Design Conference, Vol. 50, pp.141-146.

Alkan, B., Vera, D., Kaniappan Chinnathai, M. and Harrison, R. (2017) 'Assessing complexity of component-based control architectures used in modular automation systems', International Journal of Production Economics, Vol. 9, No. 1, pp.393-402.

Aqlan, F., Ahmed, A., Ashour, O., Shamsan, A. and Hamasha, M.M. (2017) 'An approach for rush order acceptance decisions using simulation and multi-attribute utility theory', European Journal of Industrial Engineering, Vol. 11, No. 5, pp.613-630.

Avram, F., Bertsimas, D. and Ricard, M. (1995) 'Fluid models of sequencing problems in open queueing networks: an optimal control approach', Institute for Mathematics and its Applications, Vol. 71, p.199.

Badrous, S.N.S. (2011) Complexity of Products and their Assembly Systems, $\mathrm{PhD}$ thesis, University of Windsor.

Bar-Yam, Y. (1997) Dynamics of Complex Systems, Addison-Wesley Reading, MA, Vol. 213.

Bilge, Ü., Albey, E., Beşikci, U., Erbatur, K. and Arslan, A.N. (2015) 'Mathematical models for FMS loading and part type selection with flexible process plans', European Journal of Industrial Engineering, Vol. 9, No. 2, pp.171-194.

Calinescu, A. (2002) Manufacturing Complexity : an Integrative Information-Theoretic Approach, $\mathrm{PhD}$ thesis, University of Oxford. 
Calinescu, A., Efstathiou, J., Schirn, J. and Bermejo, J. (1998) 'Applying and assessing two methods for measuring complexity in manufacturing', Journal of the Operational Research Society, Vol. 49, No. 7, pp.723-733.

Calinescu, A., Efstathiou, J., Sivadasan, S., Schirn, J. and Huatuco, H. (2000) 'Complexity in manufacturing: an information theoretic approach', Proceedings of the International Conference on Complexity and Complex Systems in Industry, pp.30-44.

Chinnathai, M.K., Alkan, B. and Harrison, R. (2017) 'Convertibility evaluation of automated assembly system designs for high variety production', Procedia CIRP, Vol. 60, pp.74-79.

Cho, S., Alamoudi, R. and Asfour, S. (2009) 'Interaction-based complexity measure of manufacturing systems using information entropy', International Journal of Computer Integrated Manufacturing, Vol. 22, No. 10, pp.909-922.

Chryssolouris, G., Efthymiou, K., Papakostas, N., Mourtzis, D. and Pagoropoulos, A. (2013) 'Flexibility and complexity: is it a trade-off?', International Journal of Production Research, Vol. 51, Nos. 23-24, pp.6788-6802.

Chryssolouris, G., Giannelos, N., Papakostas, N. and Mourtzis, D. (2004) 'Chaos theory in production scheduling', CIRP Annals - Manufacturing Technology, Vol. 53, No. 1, pp.381-383.

Dai, J.G. (1995) 'On positive Harris recurrence of Multiclass queueing networks: a unified approach via fluid limit models', The Annals of Applied Probability, Vol. 5, No. 1, pp.49-77.

De Toni, A.F., Nardini, A., Nonino, F. and Zanutto, G. (2001) 'Complexity measures in manufacturing systems', Proceedings of the European Conference on Complex Systems, November 2005.

Deif, A.M. and ElMaraghy, H.a. (2009) 'Modelling and analysis of dynamic capacity complexity in multi-stage production', Production Planning and Control, Vol. 20, No. 8, pp.737-749.

Deshmukh, A.V., Talavage, J.J. and Barash, M.M. (1998) 'Complexity in manufacturing systems part 1 : analysis of static complexity 1 introduction', IIE Transactions, Vol. 30, No. 7 , pp.645-655.

Ding, R. and Sun, Y-M. (2012) 'An entropy approach to structural and operational evaluation of manufacturing resource organization modes', Industrial Engineering Journal/Gongye Gongcheng, Vol. 15, No. 3, pp.69-74.

Donner, R., Scholz-Reiter, B. and Hinrichs, U. (2008) 'An entropy approach to structural and operational evaluation of manufacturing resource organization modes', Journal of Manufacturing Systems, Vol. 27, No. 2, pp.84-99.

Efstathiou, J., Calinescu, A. and Blackburn, G. (2002) 'A web-based expert system to assess the complexity of manufacturing organizations', Robotics and Computer-Integrated Manufacturing, Vol. 18, Nos. 3-4, pp.305-311.

Efthymiou, K. (2013) On the Assessment of Manufacturing Systems Complexity, PhD thesis, University of Patras.

Efthymiou, K., Mourtzis, D., Pagoropoulos, A., Papakostas, N. and Chryssolouris., G. (2016) 'Manufacturing systems complexity analysis methods review', International Journal of Computer Integrated Manufacturing, Vol. 29, No. 9, pp.1025-1044.

Efthymiou, K., Pagoropoulos, A., Papakostas, N., Mourtzis, D. and Chryssolouris, G. (2012) 'Manufacturing systems complexity review: challenges and outlook', Procedia CIRP, Vol. 3, pp.644-649.

Efthymiou, K., Pagoropoulos, A., Papakostas, N., Mourtzis, D. and Chryssolouris, G. (2014) 'Manufacturing systems complexity : an assessment of manufacturing performance indicators unpredictability ', CIRP Journal of Manufacturing Science and Technology, Vol. 7, No. 4, pp.324-334.

Efthymiou, K., Papakostas, N., Mourtzis, D. and Chryssolouris, G. (2009) 'Fluid dynamics analogy to manufacturing systems', in 42nd CIRP Conference on Manufacturing Systems.

EIMaraghy, W.H. and Urbanic, R.J. (2014) 'Assessment of manufacturing operational complexity', CIRP Annals - Manufacturing Technology, Vol. 53, No. 1, pp.401-406. 
ElMaraghy, H.A. (2005) 'Flexible and reconfigurable manufacturing systems paradigmsitle', International Journal of Flexible Manufacturing Systems, Vol. 17, No. 4, pp.261-276.

ElMaraghy, H.A. (2006) 'A complexity code for manufacturing systems', ASME 2006 International Manufacturing Science and Engineering Conference, Vol. 2006, pp.625-634.

ElMaraghy, H.A., Samy, S.N. and Espinoza, V. (2010) ‘A classification code for assembly systems', 3rd CIRP Conference on Assembly Technologies and Systems.

ElMaraghy, H., Algeddawy, T., Samy, S.N. and Espinoza, V. (2014) 'A model for assessing the layout structural complexity of manufacturing systems', Journal of Manufacturing Systems, Vol. 33, No. 1, pp.51-64.

ElMaraghy, H.A., Kuzgunkaya, O. and Urbanic, R.J. (2005) 'Manufacturing systems configuration complexity', CIRP Annals - Manufacturing Technology, Vol. 54, No. 1, pp.445-450.

ElMaraghy, H., Schuh, G., ElMaraghy, W. and Piller, F. (2013) 'Product variety management', CIRP Annals-Manufacturing Technology, Vol. 62, No. 2, pp.629-652.

ElMaraghy, W., Elmaraghy, H., Tomiyama, T. and Monostori, L. (2012) 'Complexity in engineering design and manufacturing', CIRP Annals-Manufacturing Technology, Vol. 61, No. 2, pp.793-814.

ElMaraghy, W.H. and Urbanic, R.J. (2003) 'Modelling of manufacturing systems complexity', CIRP Annals-Manufacturing Technology, Vol. 52, No. 1, pp.363-366.

Espinoza, V., ElMaraghy, H., AlGeddawy, T. and Samy, S.N. (2012) 'Assessing the structural complexity of manufacturing systems layout', Proceedings of the 4th CIRP Conference on Assembly Technologies and Systems, Vol. 18, No. 2, pp.65-70.

Falck, A-C., Örtengren, R. and Rosenqvist, M. (2014) 'Assembly failures and action cost in relation to complexity level and assembly ergonomics in manual assembly (part 2)', International Journal of Industrial Ergonomics, Vol. 44, No. 3, pp.455-459.

Falck, A-C., Örtengren, R. and Rosenqvist, M. (2012) 'Relationship between complexity in manual assembly work, ergonomics and assembly quality', in NES2012 Ergonomics for Sustainability and Growth.

Fässberg, T.,Fasth, A., Hellman, F., Davidsson, A. and Stahre, J. (2012) 'Interaction between complexity, quality and cognitive automation', Proceedings of the 4th CIRP Conference on Assembly Technologies and Systems, Vol. 2, pp.145-150.

Fast-Berglund, Å., Fässberg, T., Hellman, F., Davidsson, A. and Stahre, J. (2013) 'Relations between complexity, quality and cognitive automation in mixed-model assembly', Journal of Manufacturing Systems, Vol. 32, No. 3, pp.449-455.

Fathi, M., Álvarez, M.J. and Rodríguez, V. (2016) 'A new heuristic-based bi-objective simulated annealing method for U-shaped assembly line balancing', European Journal of Industrial Engineering, Vol. 10, No. 2, pp.145-169.

Frizelle, G. and Suhov, Y.M. (2008) 'The measurement of complexity in production and other commercial systems', Proceedings of the Royal Society A: Mathematical, Physical and Engineering Sciences, Vol. 464, pp.2649-2668.

Frizelle, G. and Suhov, Y.M. (2011) 'An entropic measurement of queueing behaviour in a class of manufacturing operations', Proceedings of the Royal Society A: Mathematical, Physical and Engineering Sciences, Vol. 457, No. 2011, pp.159-1601.

Frizelle, G. and Woodcock, E. (1995) 'Measuring complexity as an aid to developing operational strategy', International Journal of Operations and Production Management, Vol. 15, No. 5, pp.26-39.

Fujimoto, H., Ahmed, A., Iida, Y. and Hanai, M. (2003) 'Assembly process design for managing manufacturing complexities because of product varieties', International Journal of Flexible Manufacturing Systems, Vol. 15, No. 4, pp.283-307.

Gabriel, A.J. (2007) The Effect of internal Static Manufacturing Complexity on Manufacturing Performance, $\mathrm{PhD}$ thesis, Clemson University. 
Gabriel, A.J. (2013) 'Manufacturing complexity : the effects of common attributes of manufacturing system design on performance', Journal of Management Information and Decision Sciences, Vol. 16, No. 1, pp.75-97.

Garbie, I.H. and Shikdar, A. (2010) 'Design for manufacturing systems complexity: a perspective approach', ASME 2010 10th Biennial Conference on Engineering Systems Design and Analysis, Vol. 4, pp.751-762.

Giannelos, N., Papakostas, N., Mourtzis, D. and Chryssolouris, G. (2007) 'Dispatching policy for manufacturing jobs and time-delay plots', International Journal of Computer Integrated Manufacturing, Vol. 20, No. 4, pp.329-337.

Gotzfried, M. (2013) Managing Complexity Induced by Product Variety in Manufacturing Companies. Complexity Evaluation and Integration in Decision-Making, $\mathrm{PhD}$ thesis, University of St. Gallen.

Guimaraes, T., Martensson, N., Stahre, J. and Igbaria, M. (1999) 'Empirically testing the impact of manufacturing system complexity on performance', International Journal of Operations and Production Management, Vol. 19, No. 12, pp.1254-1269.

Han, P., Ma, L.L., Wu, W.J. and Liu, C. (2011) 'Research on influence factors and levels of automobile manufacturing system complexity', in 2011 IEEE 18th International Conference on Industrial Engineering and Engineering Management, IE and EM 2011, number PART 1, IEEE, pp.186-190.

Hu, S.J., Zhu, X., Wang, H. and Koren, Y. (2008) 'Product variety and manufacturing complexity in assembly systems and supply chains', CIRP Annals-Manufacturing Technology, Vol. 57, pp. $45-48$.

Huaccho Huatuco, L., Efstathiou, J., Calinescu, A., Sivadasan, S. and Kariuki, S. (2009) 'Comparing the impact of different rescheduling strategies on the entropic-related complexity of manufacturing systems', International Journal of Production Research, Vol. 47, No. 15, pp.4305-4325.

Huaccho Huatuco, L., Efstathiou, J., Sivadasan, S. and Calinescu, A. (2001) 'The value of dynamic complexity in manufacturing systems', International Conference of the Production and Operations Management Society, pp.180-188.

Huang, H. (2007) Facility Layout using Layout Modules, $\mathrm{PhD}$ thesis, The Ohio State University.

Jenab, K. and Liu, D. (2010) 'A graph-based model for manufacturing complexity', International Journal of Production Research, Vol. 48, No. 11, pp.3383-3392.

Katzorke, I. and Pikovsky, A. (2000) 'Chaos and complexity in a simple model of production dynamics', Discrete Dynamics in Nature and Society, Vol. 5, No. 3, pp.179-187.

Kim, Y-S. (1999) A System Complexity Approach for the Integration of Product Development and Production System Design, Doctoral dissertation, Massachusetts Institute of Technology.

Klir, G.J. (1985) 'Complexity: some general observations', Systems Research, Vol. 2, No. 2, pp.131-140.

Kreimeyer, M.F. (2009) 'A structural measurement system for engineering design processes', Dr. Hut, München.

Kuzgunkaya and ElMaraghy (2006) 'Assessing the structural complexity of manufacturing systems configurations', International Journal of Flexible Manufacturing Systems, Vol. 18, No. 2, pp.145-171.

Lee, T. (2003) Complexity Theory in Axiomatic Design, PhD thesis, Massachusetts Institute of Technology.

Lempel, A. and Ziv, J. (1976) 'On the complexity of finite sequences', IEEE Transactions on Information Theory, Vol. 22, No. 1, pp.75-81.

Liu, H., Xu, K. and Pan, Z. (2015) 'Modeling and application of mixed model assembly system complexity introduced by auto-body personalization', The International Journal of Advanced Manufacturing Technology, Vol. 93, Nos. 1-4, pp.43-54. 
Liu, J., Tu, H., Zhang, H., Xia, F. and Yu, D. (2008) Research on Measurement Entropy-Based of Equipment Management Complexity and Its Application in Production Planning, Springer Berlin Heidelberg, pp.604-611.

Liu, P. and Li, Z. (2012) 'Task complexity: a review and conceptualization framework', International Journal of Industrial Ergonomics, Vol. 42, No. 6, pp.553-568.

Lukáš, L. and Plevný, M. (2016) 'Using entropy for quantitative measurement of operational complexity of supplier-customer system: case studies', Central European Journal of Operations Research, Vol. 24, No. 2, pp.371-387.

Maksimović, R.M. and Petrović, S. (2009) 'Complexity of production structures', Facta Universitatis-series: Mechanical Engineering, Vol. 7, No. 1, pp.119-136.

Makui, A. and Aryanezhad, M.B. (2003) 'A new method for measuring the static complexity in manufacturing', Journal of the Operational Research Society, Vol. 54, No. 5, pp.555-557.

Marti, M. (2007) Complexity Management: Optimizing Product Architecture od Industrial Products, Springer Science and Business Media.

Massotte, P. (1996) 'Behavioural analysis of a complex system', The International Journal of Advanced Manufacturing Technology, Vol. 12, No. 1, pp.66-76.

Mattson, S. (2013) What is perceived as complex in final assembly? - To define, measure and manage production Complexity, $\mathrm{PhD}$ thesis, Chalmers University of Technology.

Mattsson, S., Gullander, P. and Davidsson, A. (2011) 'Method for measuring production complexity', 28th International Manufacturing Conference.

Mattsson, S., Gullander, P., Harlin, U., Bäckstrand, G., Fasth, A. and Davidsson, A. (2012) 'Testing complexity index - a method for measuring perceived production complexity', Procedia CIRP, Vol. 3, No. 1, pp.394-399.

Mattsson, S., Karlsson, M., Fast-Berglund, Å. and Hansson, I. (2014) 'Managing production complexity by empowering workers: six cases', Procedia CIRP, Vol. 17, pp.212-217.

Mattsson, S., Tarrar, M. and Fast-Berglund, А. (2016) 'Perceived production complexity-understanding more than parts of a system', International Journal of Production Research, Vol. 54, No. 20, pp.6008-6016.

Meyer, M.H. and Curley, K.F. (1995) 'The impact of knowledge and technology complexity on information systems development', Expert Systems With Applications, Vol. 8, No. 1, pp.111-134.

Ming, L.I. and Vitányi, P.M. (2014) 'Kolmogorov complexity and its applications', Algorithms and Complexity, Vol. 1, p.187.

Modrak, V. and Bednar, S. (2016) 'Entropy based versus combinatorial product configuration complexity in mass customized manufacturing', Procedia CIRP, Vol. 41, pp.183-188.

Modrak, V., Bednar, S. and Marton, D. (2013) 'Design optimization of the assembly process structure based on complexity criterion', Multimedia and Ubiquitous Engineering, Springer, Dordrecht, pp.747-753.

Mourtzis, D., Doukas, M. and Psarommatis, F. (2013) 'Design and operation of manufacturing networks for mass customization', CIRP Annals-Manufacturing Technology, Vol. 62, No. 1, pp.467-470.

Papakostas, N., Efthymiou, K., Mourtzis, D. and Chryssolouris, G. (2009) 'Modelling the complexity of manufacturing systems using nonlinear dynamics approaches', CIRP Annals-Manufacturing Technology, Vol. 58, No. 1, pp.437-440.

Papakostas, N. and Mourtzis, D. (2007) 'An approach for adaptability modeling in manufacturing-analysis using chaotic dynamics', CIRP Annals-Manufacturing Technology, Vol. 56, No. 1, pp.491-494.

Park, K. and Okudan Kremer, G.E. (2015) 'Assessment of static complexity in design and manufacturing of a product family and its impact on manufacturing performance', International Journal of Production Economics, Vol. 169, pp.215-232.

Peters, K., Worbs, J., Parlitz, U. and Wiendahl, H-P. (2004) 'Manufacturing systems with restricted buffer sizes', Nonlinear Dynamics of Production Systems, pp.39-54. 
Phukan, A., Kalava, M. and Prabhu, V. (2005) 'Complexity metrics for manufacturing control architectures based on software and information flow', Computers and Industrial Engineering, Vol. 59, No. 1, pp.1-20.

Rao, Y. and Efstathiou, J. (2006) 'Entropy-based measurement of manufacturing system complexity and its application in scheduling', Jixie Gongcheng Xuebao (Chinese Journal of Mechanical Engineering, Vol. 42, No. 7, pp.8-13.

Romano, P. (2009) 'How can fluid dynamics help supply chain management?', International Journal of Production Economics, Vol. 118, No. 2, pp.463-472.

Rong-Yi, Y. and Xiao-Jing, H. (2011) 'Phase space reconstruction of chaotic dynamical system based on wavelet decomposition', Chinese Physics B, Vol. 20, No. 2, p.020505.

Samy, S.N., Algeddawy, T. and Elmaraghy, H. (2015) 'A granularity model for balancing the structural complexity of manufacturing systems equipment and layout', Journal of Manufacturing Systems, Vol. 36, pp.7-19.

Samy, S.N. and ElMaraghy, H. (2012) 'A model for measuring complexity of automated and hybrid assembly systems', International Journal of Advanced Manufacturing Technology, Vol. 62, No. 5, pp.813-833.

Sandri, M. (1996) 'Numerical calculation of Lyapunov exponents', Mathematica Journal, Vol. 6, No. 3, pp.78-84.

Sarkis, J. (1997) 'An empirical analysis of productivity and complexity for flexible manufacturing systems', International Journal of Production Economics, Vol. 48, No. 1, pp.39-48.

Schleifenbaum, H., Uam, J.Y., Schuh, G. and Hinke, C. (2009) 'Turbulence in production systems fluid dynamics and its contributions to production theory', in Proceedings of the World Congress on Engineering and Computer Science, Vol. 2.

Schmitz, J.P.M., Van Beek, D.A. and Rooda, J.E. (2002) 'Chaos in discrete production systems?', Journal of Manufacturing Systems, Vol. 21, No. 3, pp.236-246.

Schoettl, F., Paefgen, M.C. and Lindemann, U. (2014) 'Approach for measuring change-induced complexity based on the production architecture', Procedia CIRP, Vol. 17, pp.172-177.

Scholz-Reiter, B., Freitag, M. and Schmieder, A. (2002) 'Modelling and control of production systems based on nonlinear dynamics theory', CIRP Annals-Manufacturing Technology, Vol. 51, No. 1, pp.375-378.

Schuh, G., Gartzen, T. and Wagner, J. (2015) 'Complexity-oriented ramp-up of assembly systems', CIRP Journal of Manufacturing Science and Technology, Vol. 10, pp.1-15.

Shalizi, C.R. and Crutchfield, J.P. (2001) 'Computational mechanics: pattern and prediction, structure and simplicity', Journal of Statistical Physics, Vol. 104, Nos. 3-4, pp.817-879.

Shannon, C.E. (2001) 'A mathematical theory of communication', ACM SIGMOBILE Mobile Computing and Communications Review, Vol. 5, No. 1, pp.3-55.

Sivadasan, S., Efstathiou, J., Calinescu, A. and Huatuco Huaccho, L. (2006) 'Advances on measuring the operational complexity of supplier-customer systems', European Journal of Operational Research, Vol. 171, No. 1, pp.208-226.

Sivadasan, S., Efstathiou, J., Frizelle, G., Shirazi, R. and Calinescu, A. (2002) 'An information-theoretic methodology for measuring the operational complexity of supplier-customer systems', International Journal of Operations and Production Management, Vol. 22, No. 1, pp.80-102.

Sivadasan, S., Smart, J., Huaccho Huatuco, L. and Calinescu, A. (2010) 'Operational complexity and supplier-customer integration: case study insights and complexity rebound', Journal of the Operational Research Society, Vol. 61, No. 12, pp.1709-1718.

Smart, J., Calinescu, A. and Huatuco Huatuco, L. (2013) 'Extending the information-theoretic measures of the dynamic complexity of manufacturing systems', International Journal of Production Research, January, Vol. 51, No. 2, pp.1-18.

Suh, N.P. (2005) Complexity: Theory and Applications, Oxford University Press on Demand. 
Thomé, A.M.T. and Sousa, R. (2016) 'Design-manufacturing integration and manufacturing complexity', International Journal of Operations and Production Management, Vol. 36, No. 10, pp.1090-1114.

Tomiyama, T., Damelio, V., Urbanic, R.J. and ElMaraghy, W. (2007) 'Complexity of multi-disciplinary design', CIRP Annals-Manufacturing Technology, Vol. 56, No. 1, pp.185-188.

Urbanic, R.J. and ElMaraghy, W.H.W. (2006) 'Modeling of manufacturing process complexity', Advances in Design, pp.425-436.

Vrabič, R. and Butala, P. (2011) 'Computational mechanics approach to managing complexity in manufacturing systems', CIRP Annals-Manufacturing Technology, Vol. 60, No. 1, pp.503-506.

Vrabič, R. and Butala, P. (2012) 'Assessing operational complexity of manufacturing systems based on statistical complexity', International Journal of Production Research, Vol. 50, No. 14, pp.3673-3685.

Wang, H. (2010) Product Variety Induced Complexity and Its Impact on Mixed-model Assembly Systems and Supply Chains, $\mathrm{PhD}$ thesis.

Wang, H. and Hu, S.J. (2010) 'Manufacturing complexity in assembly systems with hybrid configurations and its impact on throughput', CIRP Annals-Manufacturing Technology, Vol. 59, No. 1, pp.53-56.

Wang, H., Wang, H. and Hu, S.J. (2013) 'Utilizing variant differentiation to mitigate manufacturing complexity in mixed-model assembly systems', Journal of Manufacturing Systems, Vol. 32, No. 4, pp.731-740.

Wang, H., Zhu, X., Hu, S.J., Lin, Z. and Chen, G. (2009) 'Product family design to minimize manufacturing complexity in mixed-model assembly systems', in ASME 2009 International Manufacturing Science and Engineering Conference, pp.525-534.

Wang, H., Zhu, X., Wang, H., Hu, S.J., Lin, Z. and Chen, G. (2011) 'Multi-objective optimization of product variety and manufacturing complexity in mixed-model assembly systems', Journal of Manufacturing Systems, Vol. 30, No. 1, pp.16-27.

Wang, K., Wee, H., Gao, S. and Chung, S. (2005) 'Production and inventory control with chaotic demands', Omega, Vol. 33, No. 2, pp.97-106.

Weiss, G. (1999) 'Scheduling and control of manufacturing systems - a fluid approach', Proceedings of the Annual Alert on Conference on Communication Control and Computing, pp.557-586.

Wiendahl, H.P. and Scholtissek, P. (1994) 'Management and control of complexity in manufacturing', CIRP Annals-Manufacturing Technology, Vol. 43, No. 2, pp.533-540.

Wiendahl, H.P. and Scheffczyk, H. (1999) 'Simulation based analysis of complex production systems with methods of nonlinear dynamics', CIRP Annals-Manufacturing Technology, Vol. 48, No. 1, pp.357-360.

Windt, K., Philipp, T. and Böse, F. (2008) 'Complexity cube for the characterization of complex production systems', International Journal of Computer Integrated Manufacturing, Vol. 21, No. 2, pp.195-200.

Wu, Y., Frizelle, G. and Efstathiou, J. (2007) 'A study on the cost of operational complexity in customer supplier systems', International Journal of Production Economics, Vol. 106, No. 1, pp.217-229.

Zeltzer, L., Aghezzaf, E. and Limère, V. (2017) 'Workload balancing and manufacturing complexity levelling in mixed-model assembly lines', International Journal of Production Research, Vol. 55, No. 10, pp.2829-2844.

Zeltzer, L., Limère, V., Van Landeghem, H., Aghezzaf, E. and Stahre, J. (2013) 'Measuring complexity in mixed-model assembly workstations', International Journal of Production Research, Vol. 51, No. 15, pp.4630-4643.

Zhang, T. and Efstathiou, J. (2006) 'The complexity of mass customization systems under different inventory strategies', International Journal of Computer Integrated Manufacturing, Vol. 19, No. 5, pp.423-433. 
Zhang, Z. (2011) 'Modeling complexity of cellular manufacturing systems', Applied Mathematical Modelling, Vol. 19, No. 9, pp.423-433.

Zhang, Z. (2012) 'Manufacturing complexity and its measurement based on entropy models', International Journal of Advanced Manufacturing Technology, Vol. 62, Nos. 9-12, pp.867-873.

Zhu, X. (2009) Modeling Product Variety Induced Mcomplexity for Assembly System Design, $\mathrm{PhD}$ thesis.

Zhu, X., Hu, S.J., Koren, Y. and Marin, S.P. (2008) 'Modeling of manufacturing complexity in mixed-model assembly lines', Journal of Manufacturing Science and Engineering, Vol. 130, No. 5, p.051013.

Zhu, X., Hu, S.J., Koren, Y., Marin, S.P. and Huang, N. (2007) 'Sequence planning to minimize complexity in mixed-model assembly lines', IEEE International Symposium on Assembly and Manufacturing, ISAM'07, pp.251-258. 